\title{
Immunohistologic Detection of Estrogen and Progesterone Receptors on Paraffin Blocks of Breast Cancer: Correlation with Histological and Cytological Grade
}

\author{
Khadiza Khanam, ${ }^{1}$ Shah Md. Badruddoza, ${ }^{2}$ S.M.Asafudullah, ${ }^{3}$ \\ Md. Khalilur Rahman, ${ }^{4}$ Arefa Sultana, ${ }^{5}$ Mohd. Sultanul Abedin ${ }^{6}$
}

\begin{abstract}
Breast cancer is the second common cause of cancer death in women of our country. Treatment of breast cancer depends on a number of parameters known as pathological and biological prognostic markers. Knowledge of the tumour grade would avoid under treatment of high grade carcinomas and over treatment of low grade carcinomas. Out study evaluated the feasibility of a grading system on FNA of duct cell carcinoma (NOS) and its ability to predict the histologic grade of the surgical specimens. The two widely practice grading system; Robinson's cytological grading and Scraff Bloom Richardson histological grading system were utilized for this purpose. Various reports quote varied reproducibility, ranging from 50 to $90 \%$ correlation between histologic and cytologic grade. In this study, the correlation between histologic and cytologic grade is $\mathbf{8 6 . 3 \%}$. In this study association between grading by FNAC and histology was statistically highly significant $\left(x^{2}=27.66, d f=1, p<0.05\right)$ sensitivity $100 \%$ and specificity $58.33 \%$. Maximum correlation was noted in grade-l. Out of 53 cases 46 showed correlation between histologic and cytologic grading, only 7 cases showed no correlation. Histologic grade were higher than cytologic grade and maximum were within one grade difference. The reasons for discrepancies between cytologic and histologic grades appear to be due to lack of histologic parameter of mitosis in cytology. In this study, a total $\mathbf{5 7}$ cases of breast lump were selected for FNAC; of them 56 were female and 1 male. Out of 57 cases, 44 cases had duct cell carcinoma (DCC) and 13 cases had atypical finding such as small cells, inconspicuous nucleoli. Fifty three cases were diagnosed as DCC and lobular carcinoma by histopathological study. After confirmation of the diagnosis of breast cancer by histopathological examination ER, PR determination by immunohistochemistry was done in all $\mathbf{5 3}$ cases of breast cancer. FNAC has good sensitivity $(85.29 \%)$ and very high specificity $(100 \%)$. It can replace the open biopsy in the majority cases of clinically malignant disease.
\end{abstract}

TAJ 2018; 31: No-1: 01-08

\section{Introduction}

Breast cancer is the most common malignancyaffecting women, with more than one million cases occurring worldwide annually. Latest estimates in 2009, suggest that more than $1,050,000$ new breast cancer cases occur worldwide annually, with nearly 580, 000 cases

\footnotetext{
${ }^{1}$ Associate Professor, Department of Pathology, Rajshahi Medical College, Rajshahi

2 Professor, Department of Pathology, Rajshahi Medical College, Rajshahi

3 Professor, Department of Pathology, Rajshahi Medical College, Rajshahi

${ }^{4}$ Professor, Department of Medicine, Rajshahi Medical College, Rajshahi

${ }^{5}$ Assistant Professor, Department of Pathology, Rajshahi Medical College, Rajshahi

${ }^{6}$ Junior Consultant, Surgery, Rajshahi Medical College Hospital, Rajshahi
} 
occurring in developed countries and remaining in developing countries. ${ }^{1}$

The data from "Surveillance Epidemiology and End Results" programme of the National Cancer Institute showed that the cancer of the breast constituted $28 \%$ of all cancers in white women, $24.9 \%$ in black women in Unites States. ${ }^{2}$ Breast cancer constituted $15.58 \%$ of all cancers in women and ranked the top most position. ${ }^{3}$ A recently published report said that in Bangladesh breast cancer is the second most common cancer among women and constitutes about 13-17 percent of female cancer. ${ }^{4}$

About 22,000 women in Bangladesh are being attacked by breast cancer annually and 70 percent of them die due to lack of treatment. A lump is the first symptom in over 80 percent of all patients with lesions of the breast. Although the majority of breast lumps are not cancerous and require minimal treatment, some breast lumps require immediate attention. Prompt diagnosis and treatment of breast cancer provide better chance of long-term survival. Modern treatment options may not be available in our communities, and travel to the nearest treatment site is often expensive and time consuming. Women also report fear of rejection by their friends and families if they are diagnosed with breast cancer. ${ }^{5-6}$

Breast lump may be noncancerous (nonmalignant) or cancerous. Non-neoplastic breast lump such as cysts, fibroadenomas or pseudolumps, sclerosing variety of tubercular mastitis may be mistaken for malignancy. Both lumps can be evaluated by fine needle aspiration cytology (FNAC). ${ }^{7}$

Early diagnosis of breast cancer is possible by FNAC. FNAC of the breast lump is an important part of the triple assessment of the palpable breast lump [clinical examination, images (mammography or ultrasound) and FNAC. ${ }^{8}$

Grading is important for predicting the survival rate and mode of treatment. More than $80 \%$ of women with grade-I tumour survive 16 years whereas $<60 \%$ of women with grade II and III tumour survive for same period. ${ }^{9}$ Prognostic factors influencing the course of primary breast cancer depends on the size of the tumour, extent and spread of the tumour, microscopic features of primary tumour and cytological and histological type and grade, lymph node status and immunity of the host.

The grading system showed a high correlation with survival, as was shown in several studies. ${ }^{10}$

Cytological scoring system was evaluated as a method of predicting histological grade and disease free survival in 79 patients with primary breast carcinoma. The value of cytological grading as an indicator of 8 years disease free survival was also measured. A good correlation was found between the cytological score and histological grade in low and moderate grade tumour. ${ }^{11}$

Robinsons grading system used six criteria in the grading of breast adenocarcinoma. These are cellular dissociation, cell pleomorphism, nucleoli, nuclear margins, chromatin pattern and cell size. The grading system utilized cytologic material which were ethanol fixed and stained with Papanicolaou-stained. ${ }^{12}$

Scraff Bloom Richardson grading system on biopsy specimens is in use since $1957 .{ }^{13}$ Recently modified Scraff Bloom Richardson grading system is most widely practiced ${ }^{13-15}$, as assessment is based on nuclear grading which is a key prognostic factor. In Modified Bloom Richardson grading system mitotic index is used which needs assessment of cell volume. At present facilities for assessing cell volume is not possible in our department. So we used Scraff Bloom Richardson histological grading system. Robinson cytological grading system is simple and may correlate with the Scarff Bloom Richardsons grading systems as most of the criteria of both systems are related to nuclear characteristic. Both systems graded the duct cell carcinoma (NOS) into three grades (low, intermediate and high). So it is anticipated that there will be good correlation.

So, this study (retrospective and prospective) is designed to cytologically grade the duct cell carcinoma (NOS), which are already diagnosed by FNAC, by using Robinsons method of grading and to correlate it with histological grading of Scraff Bloom Richardson grading system. 
The neoplastic cells of breast cancer can express a variety of receptors. $70-80 \%$ of ER/ER positive ductal carcinoma ("no special type") are usually well differentiated. Most special types of breast cancer (i.e, lobular, tubular, mucinous and papillary) are also ER-positive. ${ }^{9}$ The receptor status of the breast cancer cells are useful for treatment and prognosis of the disease. Oestrogen (ER) and progesterone (PR) receptors are currently used in routine pathological assessment of breast cancer. $^{16}$

Steroid receptors are important markers for hormone dependence or responsiveness in breast cancer. The knowledge of the presence of ER and PR status of breast tumors is a useful means of predicting response to endocrine therapy. Patients with ER negative tumors are less likely to benefit from such treatment. ${ }^{17}$ "Hormone therapy should be the first line of treatment for women whose tumors show sensitivity to hormonal change."

The less advanced stage or grading of breast cancer, the more likely it is to be hormone receptor positive. High grade infiltrating breast cancers are predominantly ER and PR negative. ${ }^{18}$

If clinicians suspect the positivity or negativity of the ER/PR status from histolog ical grading can start appropriate hormone therapy for proper management of the breast cancer patients.

\section{Objectives}

The study is aimed at finding out the frequency of ER and PR status detection by Immunohistochemical technique in breast cancer patients.

\section{Materials and methods}

It was a cross sectional type of descriptive study consented in Department of pathology, Rajshahi Medical College fromJanuary 2008 to December 2009. Sample size was 53, Females and males of different age groups having a definite breast lump suspicious for malignancy admitted in Surgery Department in Rajshahi Medical College Hospital or attending outpatient department.

Inclusion criteria: Patients with duct cell carcinoma (NOS) who were initially diagnosed by
FNAC with subsequent histological confirmation were included in this study.

Exclusion criteria: Lump in pregnant and lactating mother or benign breast disease.

\section{Results}

The purpose of this study was to find out the relation of the status of ER and PR with the cytological and histological grading of breast cancer. All selected patients were female except one. Fine needle aspiration (FNA) were performed on these patients before surgery (After operation a final histological diagnosis was obtained).A total of 57 cases were obtained from clinically suspected patients of outpatient department of Rajshahi Medical College Hospital. Fifty three cases were selected after confirmation of diagnosis by histopathological examination. The cytological and histological variants as well as grading were done in selected 53 cases. Specimens were collected from the department of surgery of Rajshahi Medical College Hospital for the study from January 2008 to December 2009. ER, PR receptor profile was done in selected 53 cases in a private laboratory, Dhaka.

Among 53 cases cytomorphological study, histological variants as well as grading and ER, PR status were done and results were presented accordingly.

\section{Cytological findings of 57 cases of breast lump}

Out of 57 cases of FNAC done, 13 cases (16.25 $\%)$ were with atypical findings and remaining 44 cases $(55.00 \%)$ were duct cell carcinoma.

53 cases selected from 44 cases of ductal carcinoma and remaining 9 cases from atypical finding which were diagnosed as duct cell carcinoma by routine histopathology.

Sensitivity $=100 \%$

Positive predictive value $=92.98 \%$ 
Table 1: FNA cytological findings- Frequency of $E R, P R$ in relation to the histological grading of invasive ductal carcinoma

\begin{tabular}{|c|c|c|c|}
\hline \multirow{2}{*}{ FNAC } & \multicolumn{2}{|c|}{ Histology } & \multirow{2}{*}{ Total } \\
\cline { 2 - 3 } & Positive & Negative & \\
\hline Positive & 53 & 4 & 57 \\
\hline Negative & 00 & 00 & 00 \\
\hline Total & 53 & 4 & 57 \\
\hline
\end{tabular}

Histological pattern of study group

Out of 53 cases of the study group, 5 cases $(9.44 \%)$ were ductal carcinoma in situ, 46 cases (86.79\%) were invasive ductal carcinoma and only 2 cases (3.77\%) were invasive lobular carcinoma.

Table 2: Histological pattern of study group

\begin{tabular}{|l|c|c|}
\hline Histological findings & Frequency & Percentage \\
\hline Ductal carcinoma in situ & 5 & 9.44 \\
\hline $\begin{array}{l}\text { Invasive ductal } \\
\text { carcinoma }\end{array}$ & 46 & 86.79 \\
\hline $\begin{array}{l}\text { Invasive lobular } \\
\text { carcinoma }\end{array}$ & 2 & 3.77 \\
\hline Total & 53 & $100 \%$ \\
\hline
\end{tabular}

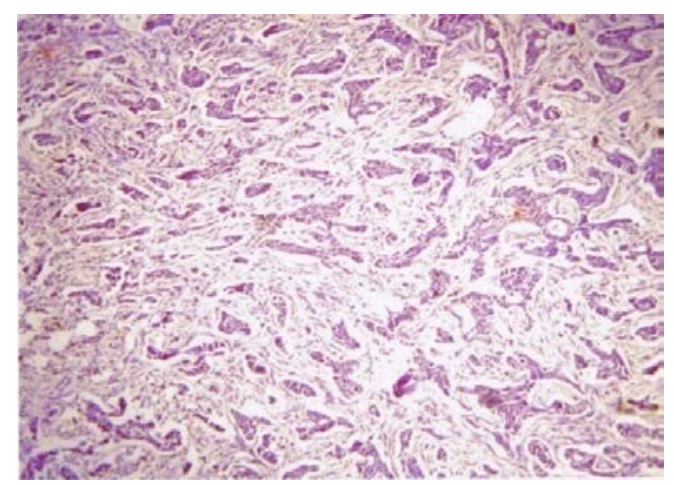

Figure 1: Photomicrograph of histological section showing poorly differentiated invasive duct cell carcinoma (NOS). (Case no-30, H\&E stain X 400).

Table 3: Histological grading of the breast carcinoma

Out of 53 cases of breast carcinoma, 14 cases (26.42\%) [Including DCIS $=5$, lobular=2] were well differentiated [grade-I] and 27 cases (50.94\%) were moderately differentiated [gradeII], 12 cases $(22.64 \%)$ were poorly differentiated [grade-III].

\begin{tabular}{|l|c|c|}
\hline $\begin{array}{l}\text { Histological grading of } \\
\text { breast carcinoma }\end{array}$ & Frequency & Percentage \\
\hline $\begin{array}{l}\text { Well differentiated } \\
\text { (Grade-I) } \\
\text { (Including DCIS = 5, } \\
\text { lobular=2) }\end{array}$ & 14 & 26.42 \\
\hline $\begin{array}{l}\text { Moderately } \\
\text { differentiated (Grade-II) }\end{array}$ & 27 & 50.94 \\
\hline $\begin{array}{l}\text { Poorly differentiated } \\
\text { (Grade-III) }\end{array}$ & 12 & 22.64 \\
\hline Total & 53 & 100.00 \\
\hline
\end{tabular}

Among well differentiated 7 cases, 5 cases (71.43\%) were ER, PR positive and 2 cases (28.57\%) were ER, PR negative. Among the moderately differentiated 27 cases, 19 cases (70.37\%) were ER, PR positive and 8 cases (29.65\%) were negative. Among poorly differentiated 12 cases, 6 cases (50\%) were ER, PR positive and 6 cases (50\%) were ER, PR negative. (Table-4)

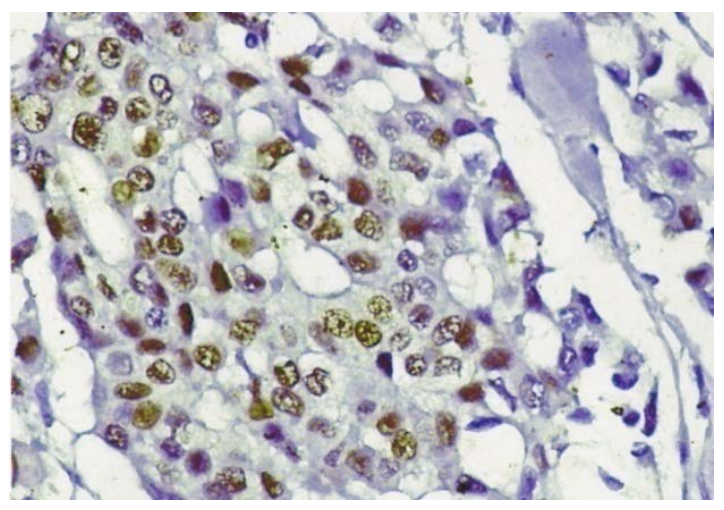

Figure-2: Photomicrograph of immun ocytochemi calstaning for PR showing moderate nuclear reactivity. (Case no-31, Paraffin sections of the formalin fixed tissue stained with DAKO clone PgR636, X 1600). 


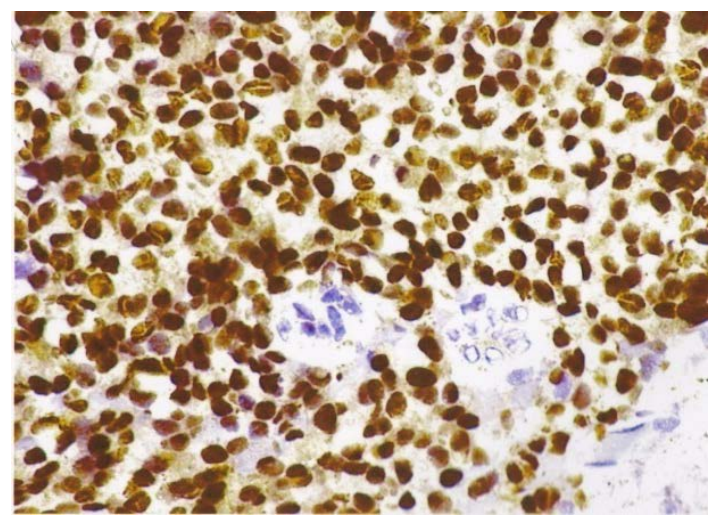

Figure-3: Photomicrograph of immunocyto chemicalstaning for ER showing strong nuclear reactivity. (Case no-35, Paraffin sections of the formalin fixed tissue stained with DAKO clone 1D5, $X$ 1600).

Table-4: Frequency of ER, PR in relation to the histological grading of invasive ductal carcinoma

\begin{tabular}{l|cc|c|c}
\hline \multirow{2}{*}{ Histological grading } & \multicolumn{2}{|c|}{ ER } & \multicolumn{2}{c}{ PR } \\
\cline { 2 - 5 } & $5(71.43 \%)$ & $2(28.57 \%)$ & 5 & 2 \\
\hline $\begin{array}{l}\text { Well differentiated-7 } \\
\text { (grade-I) }\end{array}$ & $19(70.37 \%)$ & $8(29.63 \%)$ & 19 & 8 \\
$\begin{array}{l}\text { Moderate differentiated- } 27 \\
\text { (grade-II) }\end{array}$ & $6(50 \%)$ & $6(50 \%)$ & $6(50 \%)$ & $6(50 \%)$ \\
$\begin{array}{l}\text { Poorly differentiated -12 } \\
\text { (grade-III) }\end{array}$ & 30 & 16 & 30 & 16 \\
\hline Total & 46 & & & \\
\hline
\end{tabular}

In this study, out of 53 cases, 7 cases (15.22\%) were well differentiated (Grade-I), 27 cases (58.70\% were moderately differentiated (Grade-II) and 12 cases (26.08\%) were poorly differentiated (Grade-III). Among well differentiated 7 cases, 5 cases (71.43\%) were ER/PR positive and 2 cases (28.57\%) were ER/PR negative. Among moderately differentiated 27 cases, 19 cases (70.37\%) were ER/PR positive and 8 cases (29.65\%) were ER/PR negative. Among poorly differentiated 12 cases, 6 cases (50\%) were ER/PR positive and 6 cases (50\%) were ER/PR negative.

ER/PR positive ductal carcinomas ("no special type") are usually well to moderately differentiated. ${ }^{9}$ Less differentiated tumors show significantly lower levels of ER and PR. ${ }^{17}$ In my study, ER/PR positive ductal carcinoma (no special type) are usually well to moderately differentiated which correlates with the study of UtaBerger et $\mathrm{al}^{17}$ and Lester. ${ }^{9}$ Among 53 cases of breast cancer, ER/PR positive cases were 35 cases (66.04\%) and ER/PR negative cases were 18 cases (33.96\%).In our study, we found a strong correlation between ER and PR status: when tumours were ER positive $66.04 \%$ (35/53) were also PR positive; similarly, when tumours were ER negative 33.96\% (18/35) were simultaneously PR negative. ${ }^{24}$ In a study Lisa K Dunwald $(2007)^{25}$ of USA showed 63\% combined ER/PR positivity which is very much closer to my study. Out of 53 cases 41 cases $(77.36 \%)$ were low grade [grade-I + II], 12 cases $(22.64 \%)$ were high grade [gradeIII].Among 41 cases of low grade tumour 29 cases (70.73\%) were ER/PR positive and among 12 cases of high grade tumour 6 cases (50.0\%) were ER/PR positive.

Histological grading classified into two groups, low grade (I+II) and high grade (III) ${ }^{26}$ In histological grading, out of 53 cases 41 cases (77.36\%) were low grade and 12 cases (22.64\%) were high grade. The relation between histological grading and ER/PR was found to be statistically not significant $\left(\chi^{2}=1.73, \mathrm{df}=1, p>0.05\right)$ but low histological grade tumours showed more positivity than high grade histological grade tumours. In the study of Lozowski (1987) ${ }^{26}$ showed that a strong relationship between the histologic grade and the 
demonstration of ER/PR positivity. Among 35 ER/PR positive cases, 18 cases were scoring 4-6 and 15 cases were 2-3 and remaining 2 cases were 7-8. In this study, scoring system was done by quick scores.

The prevalence of hormone receptor-positive breast cancer in Asian countries has been found to be lower than the western world. Christopher et al 2003 have documented a prevalence of $76-78 \%$ of hormone receptor-positive breast cancers in the United States. In my study the relation between histological grading and ER/PR was found to be statistically not significant $\left(\chi^{2}=1.73, \mathrm{df}=1, p>0.05\right)$ due to small number of sample size but low histological grade tumours showed more positivity than high grade histological grade tumours. In this study, clearly showed that low grade tumours express high receptor status and high grade tumours show low receptor level.

\section{Discussion}

Breast cancer is the second common cause of cancer death in women of our country. ${ }^{18}$ Treatment of breast cancer depends on a number of parameters known as pathological and biological prognostic markers. Knowledge of the tumour grade would avoid under treatment of high grade carcinomas and over treatment of low grade carcinomas.

Out study evaluated the feasibility of a grading system on FNA of duct cell carcinoma (NOS) and its ability to predict the histologic grade of the surgical specimens. The two widely practice grading system; Robinson's cytological grading and Scraff Bloom Richardson histological grading system were utilized for this purpose. Various reports quote varied reproducibility, ranging from 50 to $90 \%$ correlation between histologic and cytologic grade. ${ }^{20-22}$ In this study, the correlation between histologic and cytologic grade is $86.3 \%$.

In this study association between grading by FNAC and histology was statistically highly significant $\left(\chi^{2}=27.66, \mathrm{df}=1, \quad p<0.05\right)$ sensitivity $100 \%$ and specificity 58.33\%. Maximum correlation was noted in grade-I. Out of 53 cases 46 showed correlation between histologic and cytologic grading, only 7 cases showed no correlation. Histologic grade were higher than cytologic grade and maximum were within one grade difference. The reasons for discrepancies between cytologic and histologic grades appear to be due to lack of histologic parameter of mitosis in cytology. In this study, a total 57 cases of breast lump were selected for FNAC; of them 56 were female and 1 male. Out of 57 cases of FNAC done, 44 cases had DCC and 13 cases had atypical finding such as small cells, inconspicuous nucleoli. Fifty three cases were diagnosed as DCC and lobular carcinoma by histopathological study.

After confirmation of the diagnosis of breast cancer by histopathological examination, ER, PR status determination was done by immunohistochemistry in all 53 cases of breast cancer. FNAC has good sensitivity (85.29\%) and very high specificity (100\%). It can replace the open biopsy in majority cases of clinically malignant disease. $^{23}$

\section{Comparison of evaluation of grading of the present series with the other series:}

\begin{tabular}{|l|c|c|c|c|}
\hline Authors & No of cases & Grade-I & Grade-II & Grade-III \\
\hline Daussal et al, 1989 & 1062 & $11 \%$ & $54 \%$ & $34 \%$ \\
\hline Robinsons et al, 1994 & 281 & $34 \%$ & $44 \%$ & $22 \%$ \\
\hline Taniguchi et al, 2000 & 104 & $31.7 \%$ & $37.5 \%$ & $31.9 \%$ \\
\hline Sultana, 2005 & 80 & $41.3 \%$ & $48.8 \%$ & $10 \%$ \\
\hline Present series & 53 & $40 \%$ & $47 \%$ & $13 \%$ \\
\hline
\end{tabular}

\section{Conclusion}

The present study shows that grading of breast carcinoma on FNAC can be a useful complement to preoperative assessment of breast carcinoma. It also reveals that cytological grade can be useful when neoadjuvant therapy is planned, as an alternative to histological grading. 
Histological grading is considered as the gold standard and best parameter for predicting prognosis in clinical out-come. Better knowledge of the tumour grade would avoid over treatment of low grade carcinoma and under treatment of high grade carcinoma. Histological grading is helpful in the assessment of the ER/PR status because less differentiated (high grade) tumours show significantly lower levels of ER and PR. ${ }^{17}$ Measurement of ER/PR status of breast cancer is expansive. If clinicians suspect the positivity or negativity of the ER/PR status from histological grading can start appropriate hormone therapy for proper management of the breast cancer patients.

\section{References}

1. Bari M A, Hussain SMA, Alam S, Chowdhury RF, Nahar S, Hossain MS and Nahar S. Distribution pattern of malignancy in the oncology department of Bangabandhu Sheikh Mujib Medical University 2005. Bang.Onc.J 2009; 4(2): 59-62.

2. Young JL, Percy CL and Asire AJ: Survellance, Epidemiology and End Results: Incidence and Mortality Data 1973-77. National Cancer Inst. Cancer Supplement, January 1995; 75(1): 140-421.

3. Awal MA, Yusuff SM, Mitra $T$ et al. Pattern of malignancies among the patients attending the department of radiotherapy, Chittagong Medical College Hospital in the year 2007. Bang.Onc.J 2009; 4(2): 44-50.

4. Jasim E H. Cancer disease on rise: Developing countries more vulnerable. The New Nation-Internet Edition. May 6, 2009.

5. DR. Richard Love. Hope for breast cancer in Bangladesh. Dhaka, June 26: GR/2006.

6. Xinhua. 22,000 Bangladeshi women attacked by breast cancer annually. People's Daily Online: October 27, 2008.

7. Janet TRN. Breast cancer, Breast lumps and cysts. Wellness: November 14, 2006.

8. S.R.Walker. A randomized controlled trial comparing a $21 \mathrm{G}$ needle with a $23 \mathrm{G}$ needle for fine needle aspiration of breast lumps. J.R.Coll. Surg. Edinb., 43, October 1998, 322-323.

9. Lester SC, 2004; 'The breast' In Kumar V, Abbas AK, Fausto N, 'Robbins and Cotran Pathologic basis of disease" $7^{\text {th }}$ edition, Philadelphia, WB Saunders company; pp-1120-1153.

10. Cajulis S.R, Glenn H.R, Shyn H, Kenneth $H$, Hidvegi D.F and Maurice O Gorman, 1993; 'Simplified nuclear grading of fine needle aspirates of breast carcinoma. Concordance with corresponding histologic, nuclear grading and flow cytometric data.' Diagnostic cytopathology. Vol-11, No-2; pp-124-130.

11. Graaf D.H, Willemse P, Ladde B.E, Van Den H.A, Bergen, M. Krebber, Tjabbes $T$ and Sluiter W.J. 'Evaluation of a cytological scoring system for predicating histological grade and disease free survival in primary breast cancer' Cytopathology, 1994; 5: 293-300.

12. Robinson I, McKee G and Kissin M.W, 1995; 'Typing and grading breast carcinoma on fine needle aspiration' Diagnostic cytopathology, vol-13, no-3; pp-260-265.

13. Howell L.P, Edwards R.G. and Sullivan D.O. 1994; 'Application of the Scarff-Bloom-Richardson tumour grading system to fine needle aspiration of the breast'. Am.J.Clin.Pathol.Vol-101;pp-262-265.

14. Doussal L.V. Hulin. T, Friendaman S, Hacene K, Spyrator F and Brunet M, 1989. Prognostic value of histologic grade nuclear component of Scarff Bloom Richardson (SBR), Cancer, Vol-64, No-9; pp-19141921.

15. Rosai J, 2004 'Breast' In Rosai and Akermans Surgical Pathology, $9^{\text {th }}$ edition, vol-2. Mosby company, London; pp-1763-1863.

16. Rakha EA, Reis-Filho JS, Ellis IO. Combinatorial biomarker expression in breast cancer. Breast Cancer Res Treat 2010; 120(2): 293-308.

17. Uta Berger, Richard A. McClelland, Patricia Wilson, Geoffrey L. Greene, Mark R et al. Immunocytochemical Determination of Estrogen Receptor, Progesterone Receptor, and 1,25Dihydroxyvitamin $D_{3}$ Receptor in Breast Cancer and Relationship to Prognosis. Cancer Research 1991; 51: 239-244.

18. Christopher et al. Incidence of invasive breast cancer by hormone receptor status from 1992 to 1998. Journal of Clinical Oncology, 2003; 21(1): 2834.

19. Rai. S.M, 1991 "Study on breast cancer, the relationship of the primary tumour size and histological grading with axillary lymph node metastasis" MI.S, Banghabandhu Sheikh Mujib Medical University, Dhaka.

20. Das A.K, Kapila K, Dinda A.K. and Verma K, 2003, 'Comparative evaluation of grading of breast 
carcinomas in fine needle aspirates by two methods' Indian J Med Res, vol-118, pp-247-250.

21. Briffod M, Daussal V.L. and Spyrator F, 1997; 'Cytologic nuclear grading of fine needle cytopunctures of breast carcinoma. Comparison with histologic nuclear grading and image cytometric data.' Analytical and quantitative cytology and histology. Vol-1; pp-114-122.

22. Graaf D.H, Willemse P, Ladde B.E, Van Den H.A, Bergen, M. Krebber, Tjabbes $\mathrm{T}$ and Sluiter W.J. 'Evaluation of a cytological scoring system for predicating histological grade and disease free survival in primary breast cancer' Cytopathology, 1994; 5: 293-300.

23. Aziz M, Ahmad N, Zahid J et al. Comparison of FNAC and open biopsy in palpable breast lumps. J Coll Physicians Surg Pak. 2004; Nov 14 (11): 6546.
24. Mostafa MG, Larsen MT, Love RR. Estrogen receptor, progesterone receptor, and Her-2/neu oncogene expression in breast cancers among Bangladeshi women. National Institute for Cancer Research Hospital Dhaka. 2010; 1-8.

25. Lisa K Dunnwald, Mary Anne Rossing1, and Christopher I Li. Hormone receptor status, tumor characteristics, and prognosis: a prospective cohort of breast cancer patients. Breast Cancer Research 2007, 9:R6.

26. Lozowski MS, Mishriki Y, Chao S, Grimson R, Pai, $P$ et al. Estrogen Receptor Determination in Fine Needle Aspirates of the Breast. Correlation with Histologic Grade and Comparison with Biochemical Analysis. ActaCytologica, 1987;31(5): 557-562. 